\title{
Breath Semiconductor Metal Oxide Gas Detector using Arduino Nano
}

\author{
VM Aroutiounian* and A Hovhannisyan \\ Yerevan State University YSU, 1 Alex Manoukian Str, Armenia \\ *Corresponding author: VM Aroutiounian, Yerevan State University YSU, 1 Alex Manoukian Str, Armenia
}

\begin{tabular}{|c|c|}
\hline ARTICLE INFO & ABSTRACT \\
\hline Received: 蔧 April 02, 2020 & Keywords: Microelectronic Semiconductor Gas Sensor; Breath Analysis; Arduino \\
\hline Published: 幽 April 15, 2020 & \\
\hline
\end{tabular}

Citation: VM Aroutiounian, A Hovhannisyan.

Abbreviations: VOCs: Volatile Organic Compounds; COPD: Chronic Obstructive Pulmonary Disease; LEDs: Light Emitting Devices

Breath Semiconductor Metal Oxide Gas

Detector using Arduino Nano. Biomed J Sci \&

Tech Res 27(1)-2020. BJSTR. MS.ID.004442.

\section{Opinion}

Interest in the research of small-sized semiconductor gas sensors for medical applications has sharply increased in recent years. Requirements for such sensors are their high sensitivity, performance, and stability to low concentrations of gases, mainly exhaled by a living organism. One of the most important directions of modern medicine is non-invasive diagnostics of the patients, based on the analysis of exhaled air in a special device. Exhaled breath contains about 1000 volatile organic compounds (VOCs) that are the products of metabolism. The exhaled gases such as acetone and $\mathrm{H} 2 \mathrm{O} 2$ can be used as sensors to diagnose various diseases. It is known that the detection of hydrogen peroxide $\mathrm{H} 2 \mathrm{O} 2$ allows getting an information about the flow of respiratory diseases (asthma, chronic obstructive pulmonary disease (COPD), lung cancer, weakened respiratory lung function, etc.) Detection of acetone $\mathrm{C} 6 \mathrm{H} 6 \mathrm{O}$ allows getting an information about the flow of the pancreas in acute pancreatitis and execute-destructive dietary and severe balance failure at lung cancer, diabetes as well as chronic liver disease and alcoholism [1].

Determination of the concentration of chemical compounds in explosives using gas sensors will allow the diagnosis of the disease already in the early stages and will make it possible to control treatment. To overcome the challenges associated with spectroscopic and mass-spectroscopy techniques for breath analysis, semiconductor gas sensors having small sizes and consuming small electric power are adopted. Note that at Yerevan State University (Department of Semiconductor Physics and Microelectronics and the Scientific Center for Semiconductor Devices and Nanoelectronics) in Armenia as a result of many years of research, semiconductor sensors of various gases have been developed. Metaloxide sensors are sensitive to vapors of acetone, ammonia, nitrogen oxides, iso-butane, hydrogen sulfide, hydrogen, various alcohols, toluene, combustible gases, hydrogen peroxide, propane, propylene glycol, formaldehyde, dimethylformamide, dichloroethane, gasoline, and carbon monoxide [1]. As part of a NATO grant, small-sized semiconductor sensors for nerve gases of chemical weapons (sarin, mustard gas) have been developed in Yerevan. Successful tests of such warfare sensors were carried out at the Czech Military Academy.

A programmable board with its own processor and Arduino Nano memory was used by us for the preparation of the breath analyzer of different diseases. It based on home-made acetone or hydrogene peroxide semiconductor sensors. The board has a couple of dozen contacts to which you can connect all kinds of components displays, light emitting devices (LEDs), sensors, motors, routers, magnetic locks, etc. A program into the Arduino processor was loaded by us what will control all of these devices according to a given algorithm, that is, the Arduino board was programmed. The 
Arduino board provided an extensibility and the ability to automate certain activities. We have chosen the Arduino Nano board. In addition to the Arduino board and the gas sensor, we needed an alarm system, a servo drive that will simulate a valve and one relay. We also added two buttons - the first one to turn the system on and off, and the second one to turn the servo on and off. The entire system is powered by finger batteries. The device diagram is shown in Figure 1. As was mentioned above, the proposed by us compact gas detectors do not require significant working heating of the sensor' substrate. For example, it can be easy transferred in a clinic or used in a car where there is a 12-volt power supply. In result, the size of the device will be reduced.

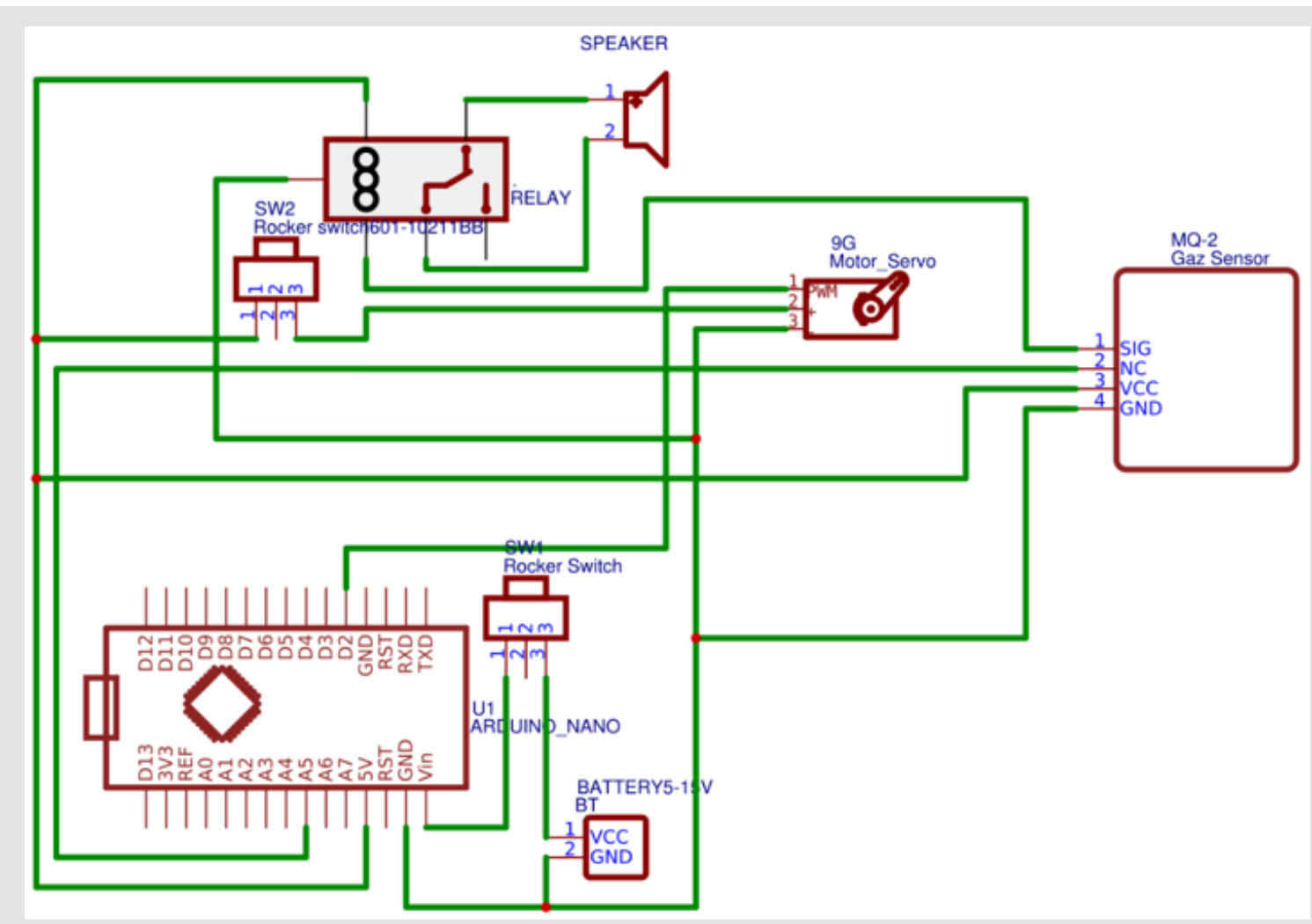

Figure 1:

\section{References}

1. Aroutiounian VM (2019) Diagnostics using microelectronic semiconductor gas sensors, Reports of National Academy of Sciences of Armenia 119(3): $264-273$.

ISSN: $2574-1241$

DOI: 10.26717/BJSTR.2020.27.004442

VM Aroutiounian. Biomed J Sci \& Tech Res

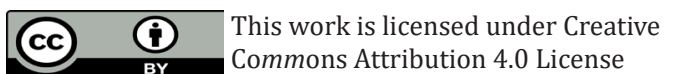

Submission Link: https://biomedres.us/submit-manuscript.php

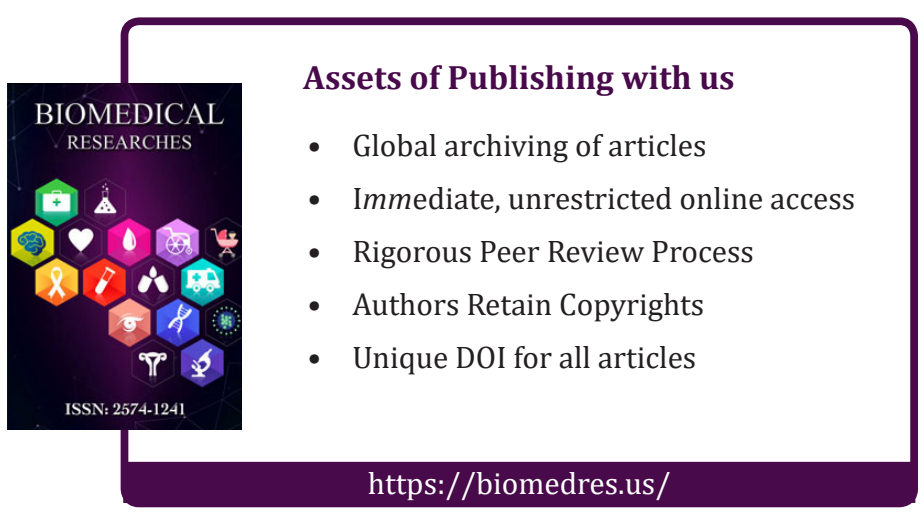

